\title{
ANALISIS SISTEM INFORMASI GEOGRAFIS (SIG) UNTUK POTENSI WISATA PANTAI DI KOTA MAKASSAR, PROVINSI SULAWESI SELATAN
}

\author{
Analysis Of Geographic Information System (Gis) For Potential \\ of Coastal Tourism In Makassar City, South Sulawesi Province
}

\section{Yulius $^{1}$ dan Taslim Arifin ${ }^{1}$}

Diterima : 9 Mei 2014

Disetujui : 27 Juni 2014

\begin{abstract}
Abstrak : Kota Makassar memiliki sumberdaya alam yang sangat potensial dengan pantainya yang landai dan berpasir, membujur dari utara ke selatan dan posisinya sangat strategis merupakan ibukota provinsi Sulawesi Selatan. Penelitian ini bertujuan untuk mengidentifikasi potensi wisata pantai di kota Makassar dengan menggunakan Analisis Sistem Informasi Geografis (SIG). Metode yang digunakan dalam penelitian ini adalah metode analisis spasial. Berdasarkan hasil analisis spasial, diperoleh pada daerah penelitian terbagi menjadi tiga tipe pantai yaitu: (1) pantai berpasir, (2) pantai berbakau, dan (3) pantai reklamasi. Ketiga tipe pantai tersebut dapat direkomendasikan untuk beberapa potensi aktifitas wisata seperti; (1) pantai berpasir: snorkeling, olahraga pantai (bola volley pantai, sepak bola pantai), bermain pasir, piknik, berenang, berjemur, maupun berselancar angin, (2) pantai berbakau/ bermangrove: kegiatan studi wisata, dan (3) pantai reklamasi: kegiatan memancing dan berjalan-jalan atau berlari-lari di sepanjang pantai.
\end{abstract}

Kata kunci : Sistem Informasi Geografis (SIG), tipe pantai, wisata pantai, Kota Makassar

\begin{abstract}
Makassar city, as a capital of South Sulawesi Province, has potential natural resources with its moderately sloped sandy beach, from north to south. The aims of this research is to identify the potential of coastal tourism in makassar city using GIS spatial analysis. The methods which is used in this study is spatial analysis using GIS. The result shows that Makassar coastal divided into three types, these are: (1) sandy beach, (2) mangrove beach and (3) reclamation beach. Those kind of beaches can be recommended for some tourism activities such as: (1) sandy beach: snorkeling, beach sport, beach volley ball and beach football, beach picnic, swimming, sun bathing, surfing, (2) mangrove beach: field study and (3) reclamation beach: fishing, walking and jogging on beach.
\end{abstract}

Keywords: Geographic Information System (GIS), coastal type, coastal tourism, Makassar City

\footnotetext{
${ }^{1}$ Pusat Penelitian dan Pengembangan Sumberdaya Laut dan Pesisir Badan Penelitian dan Pengembangan Kelautan dan Perikanan, Kemenerian Kelautan dan Perikanan.

Jln. Pasir Putih I Ancol Timur-Jakarta 14430, Telp (021) 64711583
} 


\section{Pendahuluan}

Wilayah pesisir memiliki arti strategis karena merupakan wilayah peralihan antara ekosistem darat dan laut, serta memiliki potensi sumberdaya alam dan jasa-jasa lingkungan yang sangat kaya, sehingga menimbulkan daya tarik bagi berbagai pihak untuk memanfaatkan sumberdayanya. Di sisi lain, sumberdaya alam pesisir ini sering bersifat multi-guna dimana berbagai kegiatan memiliki hak atas akses dan pemanfaatan sumberdaya di kawasan ini. Kawasan ini dapat dimanfaatkan sebagai tempat beraktifitas untuk penangkapan ikan dan juga kawasan ini merupakan ruang untuk melakukan aktivitas pariwisata bahari. Peranan yang besar itu menjadikan wilayah ini sangat rentan dari berbagai masalah, baik itu yang menyangkut masalah dari aspek fisik dan biologi maupun masalah yang menyangkut aspek sosial, ekonomi maupun budaya. Permasalahan ini terutama menyangkut sumberdaya alam sebagai kendala yang merupakan ekosistem penting bagi keberlanjutan hidup baik manusianya sendiri, maupun sumberdaya alam dan lingkungannya secara keseluruhan (Dahuri et. Al, 2004).

Dalam undang-undang No. 27 tahun 2007 dinyatakan bahwa wilayah pesisir adalah daerah peralihan antara ekosistem darat dan laut yang dipengaruhi oleh perubahan di darat dan laut. Hal ini menjadikan negara Indonesia memiliki potensi sumberdaya pesisir dan laut yang besar serta keanekaragaman hayati tinggi yang dapat menunjang kehidupan. Potensi yang besar ini akan dapat dinikmati oleh masyarakat secara optimal jika dilakukan pemanfatan dan pengelolaan berkelanjutan. Wisata bahari adalah jenis wisata minat khusus yang memiliki aktivitas yang berkaitan dengan kelautan, baik di atas permukaan laut (marine), maupun kegiatan yang dilakukan dipermukaan laut (submarine). Menurut Direktorat Jendral Pariwisata, wisata bahari disebut juga wisata minat khusus yaitu suatu bentuk perjalanan wisata yang mengunjungi suatu tempat karena memiliki minat atau tujuan khusus terhadap suatu objek atau kegiatan yang dapat ditemui atau dilakukan di lokasi atau daerah tujuan wisata. Wisata bahari merupakan wisata lingkungan (eco-tourism) yang berlandaskan daya tarik bahari di lokasi atau kawasan yang didominasi perairan atau kelautan (PRWLSDNH 2002).

Wisata pantai merupakan bagian dari wisata pesisir yang memanfaatkan pantai sebagai objek wisata, meliputi : (a) perjalanan yang menggunakan moda angkutan laut / air, (b) objek wisata dan aktivitas yang diselenggarakan di laut, antara lain : kegiatan memancing, lomba layar dan dayung, ski air, upacara adat yang dilakukan di laut, surfing dan sebagainya, (c) kegiatan wisata pantai yang mencakup rekreasi di wilayah perairan antara lain: kegiatan marina, hotel dan restoran selam, kapal wisata, kapal layar, pengelolaan pulau kecil, snorkelling, olahraga pantai seperti bola volley, pantai, sepak bola pantai, menikmati keindahan alam pantai, berjalan-jalan atau berlari-lari di sepanjang pantai, bermain pasir, piknik, berenang, berjemur, maupun berselancar angin, (d) Usaha penunjang kegiatan wisata pantai, antara lain : jasa penyediaan moda transportasi, pengelola pulau kecil, pengelola taman laut, hotel dan restoran terapung, pemandu wisata

Dahuri et. al (2004). Mendefinisikan pariwisata pantai sebagai kegiatan rekreasi yang dilakukan di sekitar pantai. Pariwisata semacam ini sering diasosiasikan dengan tiga 'S" yaitu Sun, Sea, Sand artinya jenis pariwisata yang menyediakan keindahan dan kenyamanan alami dari kombinasi cahaya matahari, laut dan pantai berpasir putih.

Pembangunan pariwisata bahari dan pantai pada hakikatnya adalah upaya mengembangkan dan memanfaatkan potensi objek serta daya tarik sumberdaya di kawasan pesisir dan lautan Indonesia, berupa kekayaan alam yang indah seperti pantai yang landai dan berpasir putih, keragaman flora dan fauna seperti terumbu karang dan berbagai jenis ikan hias. 
Beberapa jenis kegiatan wisata bahari dan wisata pantai pada saat ini sudah dikembangkan oleh pemerintah dan swasta, diantaranya wisata alam, pemancingan, berenang, selancar, berlayar, rekreasi pantai dan wisata pesiar. Wisata pantai terdiri dari dua kategori yaitu kategori rekreasi dan wisata mangrove.

Kota Makassar Provinsi Sulawesi Selatan memiliki wilayah perairan pesisir yang unik dan memiliki nilai cukup strategis dalam pembangunan ekonomi, baik dalam pemanfaatan ekonomi maupun ekologinya. Dalam pengelolaannya diperlukan keterpaduan antar berbagai kegiatan dalam koordinasi dan mengarahkan berbagai kegiatan yang ada di wilayah pesisir tersebut. Hal ini dimaksudkan sebagai suatu upaya secara terprogram untuk mencapai tujuan yang dapat mengharmoniskan dan mengoptimalkan antara berbagai kepentingan agar terpelihara lingkungan dan tercapainya pembangunan ekonomi.

Kota Makassar (dahulu daerah tingkat II berstatus kotamadya; dari 1971 hingga 1999 secara resmi dikenal sebagai Ujungpandang atau Ujung Pandang) adalah sebuah kotamadya dan sekaligus ibu kota provinsi Sulawesi Selatan. Secara geografis, Kota Makassar terletak di pesisir pantai barat bagian selatan Sulawesi Selatan menghadap Selat

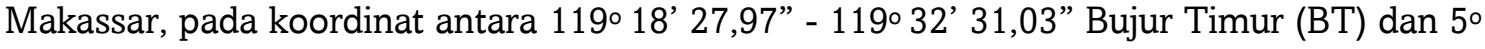
30' 18” - 5॰ 14' 49” Lintang Selatan (LS). Ketinggian kota ini bervariasi antara $0-25$ meter dari permukaan laut, suhu udara antara $20^{\circ}-32^{\circ} \mathrm{C}$, memiliki garis pantai sepanjang $32 \mathrm{~km}$ dan areal seluas $175,77 \mathrm{~km}^{2}$, serta terdiri dari 14 kecamatan, dan 143 kelurahan (PRWLSDNH, 2004). Kota ini termasuk kota kosmopolis dan kota terbesar, dengan jumlah penduduk kurang lebih 1,25 juta jiwa, banyak suku bangsa tinggal di sini. Di kota ini ada suku Makassar, Bugis, Toraja dan Mandar. Di kota ini ada pula komunitas Tionghoa yang cukup besar (BPS, 2006).

Dua sungai besar mengapit kota ini, yaitu: Sungai Tallo yang bermuara disebelah utara kota dan Sungai Jeneberang bermuara pada bagian selatan kota (PRWLSDNH, 2004). Makassar dikenal mempunyai Pantai Losari yang indah. Kota ini berbatasan dengan Selat Makassar di sebelah barat, Kabupaten Kepulauan Pangkajene di sebelah utara, Kabupaten Maros di sebelah timur dan Kabupaten Gowa di sebelah selatan (BPS, 2006). Topografi wilayah pada umumnya berupa dataran rendah dan daerah pantai. Dataran rendah merupakan wilayah yang paling dominan di daerah ini, sehingga pada musim penghujan, sebagian besar wilayah kota ini tergenang air (PRWLSDNH, 2004).

Pada kawasan pesisir pantai Kota Makassar, terdapat 3 komponen ekosistem, yaitu estuari, mangrove dan terumbu karang. Ekosistem estuari berada di muara sungai Jeneberang dan aliran pasang surut. Ekosistem mangrove banyak dipengaruhi oleh ekosistem estuari sehingga keberadaannya di pantai Kota Makassar berasosiasi dengan ekosistem estuari, khususnya di mauara sungai Tallo. Ekosistem terumbu karang mendominasi seluruh gugusan pulau yang berada di perairan Makassar, termasuk dalam kelompok Kepulauan Spermonde (PRWLSDNH, 2004).

Kondisi dan jenis pantai di Indonesia secara sederahana dapat dikelompokan atas pantai berpasir, pantai berlumpur/mangrove, pantai berawa dan pantai berbatu (Bemmelen, 1970). Kota Makassar memiliki sumberdaya alam yang sangat potensial dengan pantainya yang landai dan berpasir, membujur dari utara ke selatan dan posisinya sangat strategis merupakan ibukota provinsi Sulawesi Selatan.

Kota Makassar merupakan wilayah yang cukup memiliki keanekaragaman pemanfaatan laut terutama pesisirnya. Keanekaragaman itu terlihat dari adanya kawasan pelabuhan, industri, permukiman, dan wisata. Secara langsung maupun tidak langsung, jenis kegiatan yang berada di wilayah ini telah merubah tipe pantainya, disamping perubahan yang diakibatkan oleh dinamika alami pesisir. Penelitian ini bertujuan untuk mengidentifikasi potensi wisata pantai di kota Makassar dengan menggunakan Analisis Sistem Informasi Geografis (SIG). 


\section{Bahan dan Metode}

\section{Waktu dan Tempat Penelitian}

Penelitian ini dilaksanakan di Kota Makassar, Provinsi Sulawesi Selatan (Gambar 1). Penelitian dilaksanakan pada bulan Mei 2010.

\section{Bahan dan Alat Penelitian}

Bahan dan alat penelitian yang digunakan yaitu; citra batimetri perairan makasar tahun 2008, GPS untuk mendapatkan posisi geografis, kamera digital untuk pemotretan kondisi eksisting di lapangan dan alat tulis.

\section{Pengumpulan Data}

Data yang digunakan meliputi data sekunder dan data primer. Data primer diperoleh dengan cara melakukan survei dan observasi langsung di lapangan (Tabel 1). Data sekunder diperoleh dari Bappeda Kota Makassar, PRWLSDNH BRKP-DKP, Dinas Kimpraswil Kota Makassar dan Universitas Hasanudin (Tabel 2). Dari data sekunder banyak diperoleh gambaran kondisi fisik dan garis pantai yang terdapat di Kota Makassar secara menyeluruh.

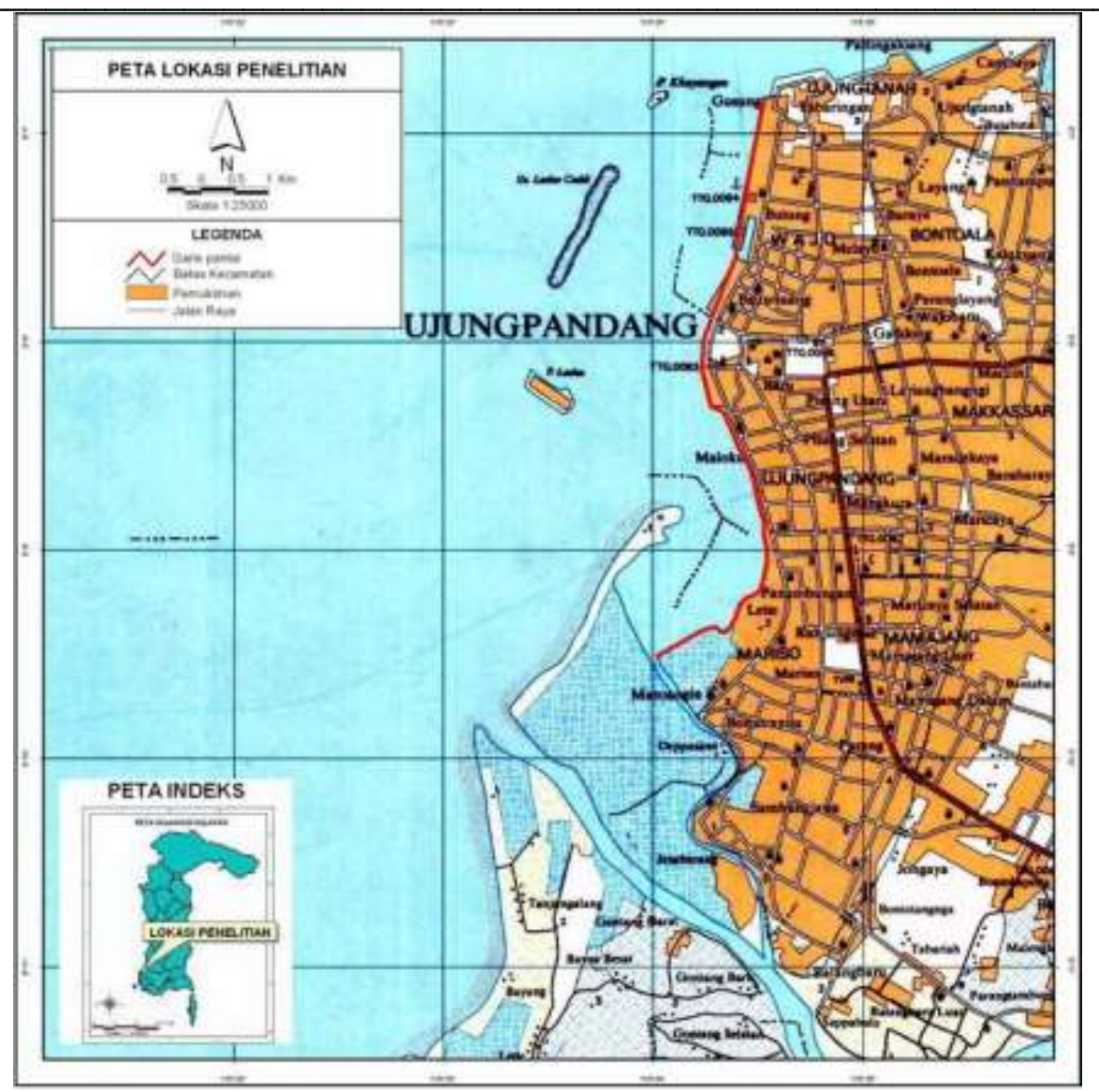


Tabel 1. Pengumpulan Data Primer

\begin{tabular}{lllll}
\hline No. & Jenis Data & $\begin{array}{l}\text { Teknik } \\
\text { Pengumpulan }\end{array}$ & $\begin{array}{l}\text { Alat yang } \\
\text { digunakan }\end{array}$ & $\begin{array}{c}\text { Lokasi } \\
\text { Pengumpulan Data }\end{array}$ \\
\hline 1. & $\begin{array}{l}\text { Data tipe atau } \\
\text { karakteristik pantai }\end{array}$ & $\begin{array}{l}\text { Pengamatan } \\
\text { secara visual dan } \\
\text { pemotretan }\end{array}$ & Kamera digital & Pantai Kota Makassar \\
2. & Posisi geografis & $\begin{array}{l}\text { Plotting } \\
\text { GPS Garmin 12 XL }\end{array}$ & Pantai Kota Makassar \\
\hline
\end{tabular}

Tabel 2. Pengumpulan Data Sekunder

\begin{tabular}{|c|c|c|c|c|}
\hline No. & Jenis Data & $\begin{array}{l}\text { Teknik } \\
\text { Pengumpulan }\end{array}$ & $\begin{array}{l}\text { Skala/ } \\
\text { Resolusi }\end{array}$ & $\begin{array}{l}\text { Sumber } \\
\text { Data }\end{array}$ \\
\hline 1. & $\begin{array}{l}\text { Citra Landsat Batimetri } \\
\text { Perairan Makasar }(2008)\end{array}$ & Inventarisasi & Resolusi $30 \mathrm{~m}$ & Universitas Hasanudin \\
\hline 2. & $\begin{array}{l}\text { Karakteristik Pantai (2006) } \\
\text { Peta RTRW (2004) }\end{array}$ & $\begin{array}{lr}\text { profil dasar } \\
\text { daerah penelitian }\end{array}$ & $\begin{array}{l}- \\
1: 50.000\end{array}$ & $\begin{array}{l}\text { Dinas Kimpraswil Kota } \\
\text { Makassar, BRKP-DKP } \\
\text { Bappeda Kota Makassar }\end{array}$ \\
\hline
\end{tabular}

\section{Analisis Data}

Analisis data dilakukan dengan menggunakan Sistem Informasi Geografi (SIG), yaitu sistem informasi spasial berbasis komputer dengan melibatkan perangkat lunak Arc View3.3. Pada analisis ini prinsipnya berupa basis data dari data primer maupun data sekunder dengan data aktual tahun 2010 seperti data fisik dan data garis pantai

\section{Hasil dan Pembahasan}

Pemetaan tipe pantai di kawasan pesisir Kota Makassar mengacu pada klasifikasi pantai dari Dolan (1972) dan dilakukan secara visual mulai dari ujung pantai utara daerah penelitian secara menerus hingga ke arah selatan dari ujung daerah penelitian.

Berdasarkan hasil pengamatan secara visual perbedaan mencolok terjadi pada daerah muara sungai Tallo. Di muara sungai ini pola arus yang ada sangat berperan penting bagi dinamika sedimentasi dan polutan yang mengalir keluar dari Muara Sungai. Arus susur pantai yang terjadi di daerah penelitian dibangkitkan oleh ombak yang datangnya menuju arah baratdaya - barat dan membentuk sudut terhadap garis pantai. Kondisi pantai akibat perbedaan tingkat sedimentasi menyebabkan perbedaan tipe pantai yang sangat berbeda. Pada pantai yang tersusun oleh sedimentasi batuan yang memiliki tipe pantai berpasir, hal ini terjadi di daerah yang langsung berhadapan dengan perairan Selat Makassar, sedangkan pada pantai yang tersusun oleh sedimentasi lumpur yang memiliki tipe pantai berbakau/mangrove.

Berdasarkan hasil analisis secara spasial, diperoleh bahwa untuk tipe pantai pada daerah penelitian dapat dibagi menjadi tiga tipe, yaitu: (1) pantai berpasir, (2) pantai berbakau/ bermangrove, dan (3) pantai reklamasi, seperti ditunjukan pada Gambar 2. 


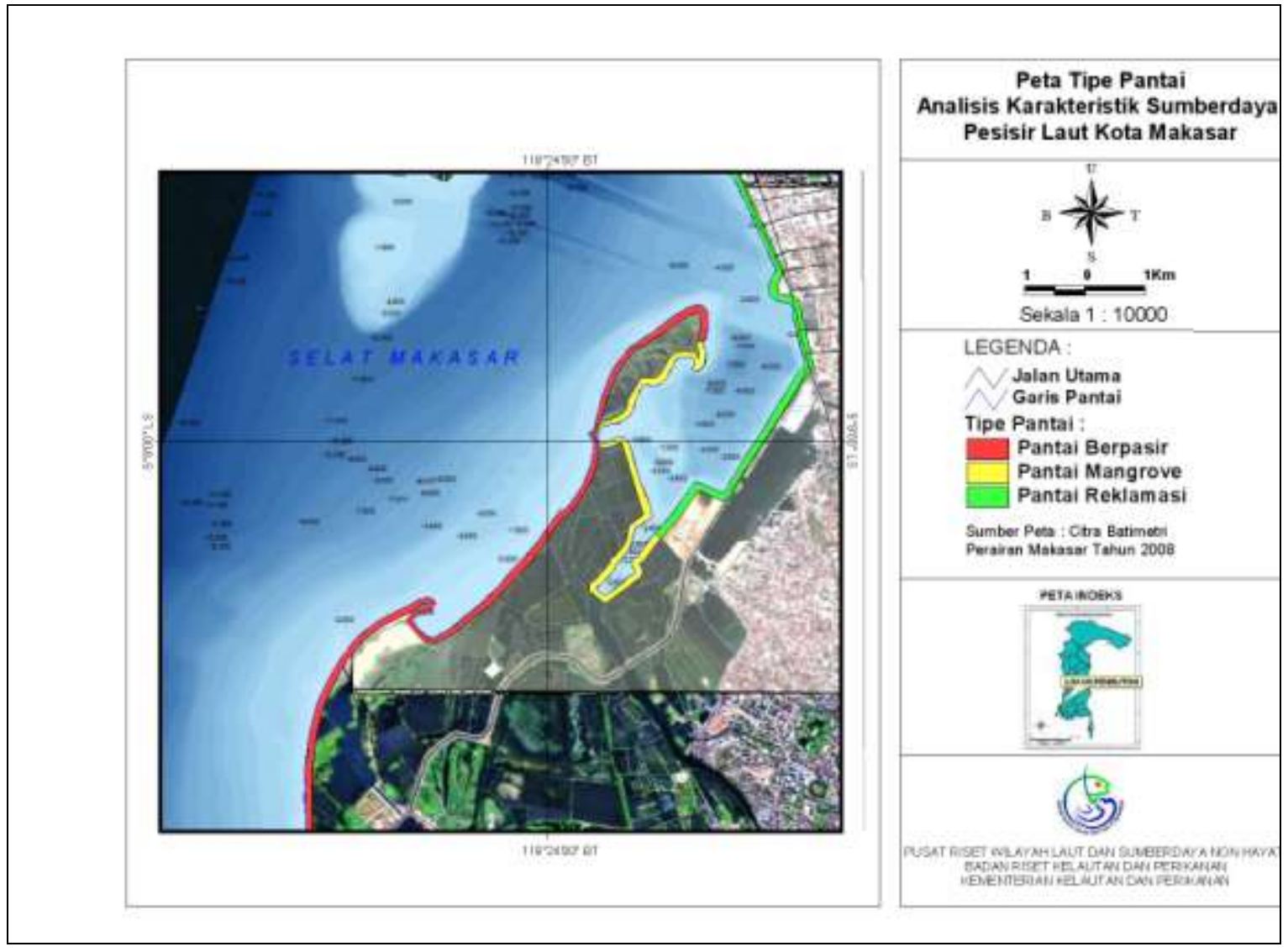

\section{Gambar 2. Peta tipe pantai Kota Makassar}

Berdasarkan jenis pantai, unit-unit geomorfologi serta litologi penyusunnya, berikut dibahas mengenai karakteristik pantai di wilayah penelitian Kota Makassar dan sekitarnya, sebagai berikut:

Wilayah pantai Kota Makassar terbagi atas 3 (tiga) macam jenis pantai:

a. Pantai berpasir

Pantai berpasir ditemukan tersebar mendominasi hampir di seluruh bagian kota. Pantai ini dicirikan oleh pasir pantai sebagai batas pesisir (Gambar 3). Pasir berukuran halus, warna hitam kecoklatan, lebar paras pantai bervariasi dari $3-24$ meter. Ukuran pasir halus ditemui hampir diseluruh bagian pantai. Penggunaan lahan di sekitar pantai berpasir adalah kawasan wisata, permukiman dan pertokoan. Berdasarkan pengamatan garis pantai di wilayah teluk, dapat diketahui telah terjadi perubahan garis pantai akibat proses geomorfologi berupa abrasi air laut.

Pantai berpasir di Kota Makassar dapat direkomendasikan untuk beberapa potensi aktifitas wisata seperti; snorkeling, olahraga pantai (bola volley pantai, sepak bola pantai), bermain pasir, piknik, berenang, berjemur, maupun berselancar angin. 


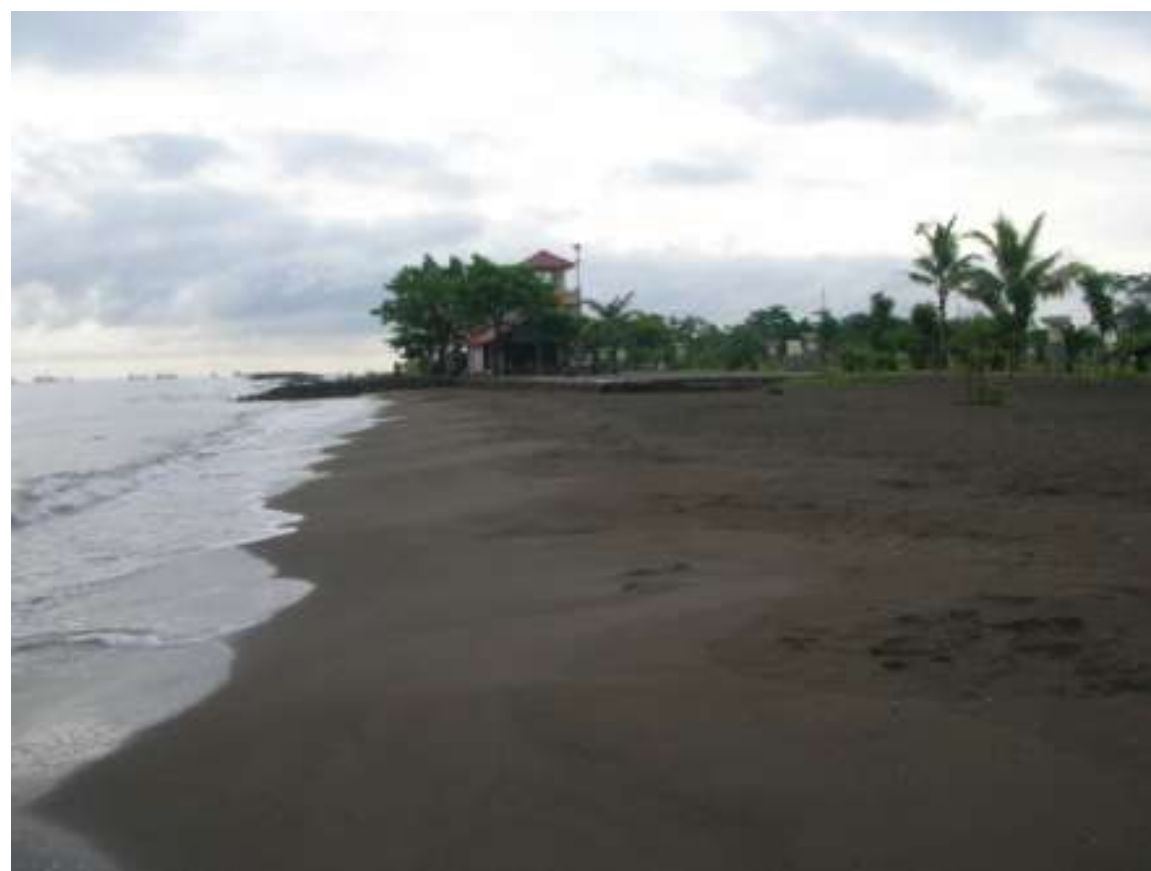

Gambar 3. Jenis pantai berpasir di wilayah Kota Makassar

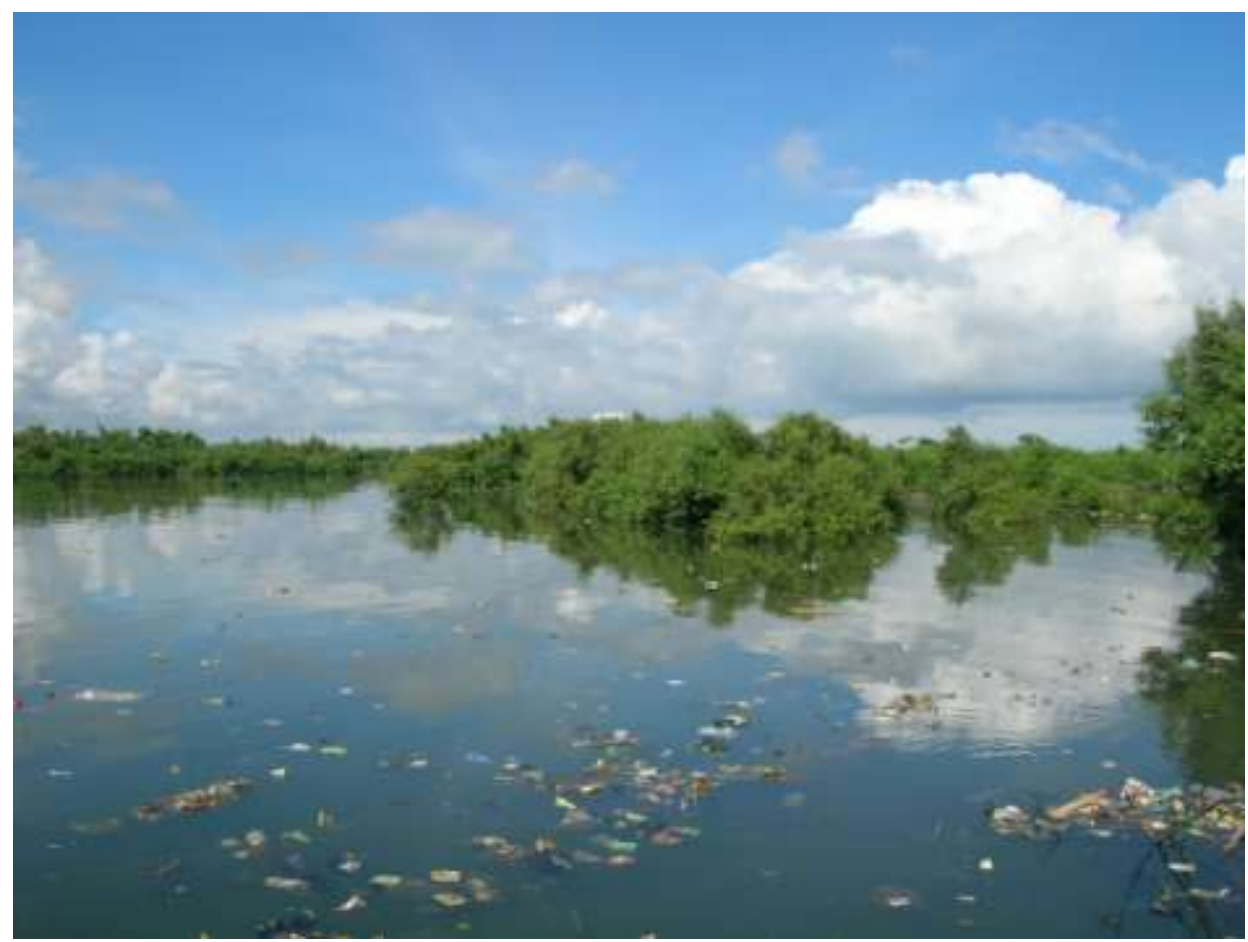

Gambar 4. Jenis pantai berbakau di wilayah Kota Makassar

TATA LOKA - VOLUME 16 NOMOR 3 - AGUSTUS 2014 
b. Pantai berbakau/bermangrove

Pantai berlumpur atau mangrove dijumpai di sekitar wilayah ekosistem estuari sehingga keberadaannya di pantai Kota Makassar berasosiasi dengan ekosistem estuari, khususnya di mauara sungai Tallo. Disini terlihat batas yang jelas antara laut dan vegetasi mangrove sebagai batas pesisir (Gambar 4), dengan kerapatan yang sedang hingga tebal. Sesuai dengan vegetasi yang tumbuh diatasnya, terlihat bahwa kandungan lumpur yang menjadi substrat tempat tumbuh vegetasi ini menjadi bagian yang tak terpisahkan dari karakteristik pantainya. Pantai berlumpur atau mangrove pada daerah penelitian tersebut dapat direkomendasikan untuk beberapa potensi aktifitas wisata seperti; kegiatan studi wisata.

\section{c. Pantai reklamasi}

Genesa pantai yang tersusun oleh pasir dan semen merupakan hal utama pembentuk pantai jenis ini. (Gambar 5). Kemiringan tebing mencapai $\pm 90^{\circ}$. Dominasi pantai jenis ini terlihat terutama di bagian utara Kota Makassar. Pantai reklamasi di Kota Makassar dapat direkomendasikan untuk beberapa potensi aktifitas wisata seperti;: kegiatan memancing dan berjalan-jalan atau berlari-lari di sepanjang pantai.

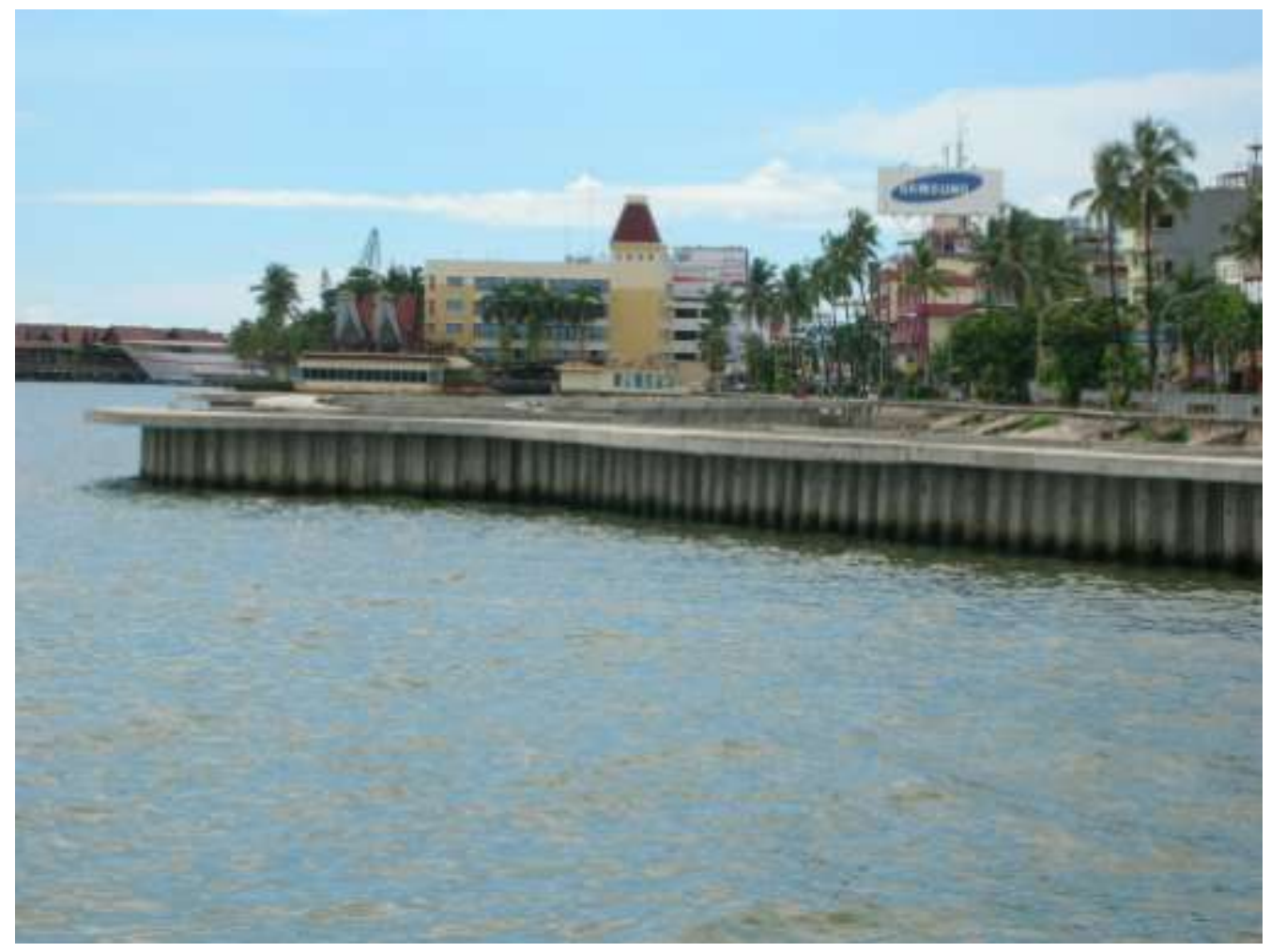

Gambar 5. Jenis pantai reklamasi di wilayah Kota Makassar

\section{Kesimpulan}

Berdasarkan hasil analisis spasial, diperoleh pada daerah penelitian terbagi menjadi tiga tipe pantai yaitu: (1) pantai berpasir, (2) pantai berbakau, dan (3) pantai reklamasi. Ketiga tipe pantai tersebut dapat direkomendasikan untuk beberapa potensi aktifitas wisata seperti; (1) pantai berpasir: snorkeling, olahraga pantai (bola volley pantai, sepak bola pantai), bermain pasir, piknik, berenang, berjemur, maupun berselancar angin, (2) pantai 
berbakau/ bermangrove: kegiatan studi wisata, dan (3) pantai reklamasi: kegiatan memancing dan berjalan-jalan atau berlari-lari di sepanjang pantai.

\section{Ucapan Terima Kasih}

Ucapan terima kasih kepada Badan Riset Kelautan dan Perikanan, KKP atas bantuan dana untuk menyelesaikan penelitian ini.

\section{Daftar Pustaka}

Anonimous, 2007, Undang-Undang Republik Indonesia Nomor 27 Tahun 2007 Tentang Pengelolaan Wilayah Pesisir Dan Pulau-Pulau Kecil.

[BPS] Badan Pusat Statistik. 2006. Monografi Kota Makassar. Makassar: BPS Kota Makassar.

Bemmelen R.W. Van., 1970, The Geology Of Indonesia Vol. 1A, General Geology Of Indonesia and Adjacent Archipelagos, Second Edition, Martinus Nijhoff/The Hague, p.164-167

Dahuri R, Jacub R, Sapta PG. 2004. Pengelolaan Sumberdaya Wilayah Pesisir dan Lautan Secara Terpadu. Jakarta: PT. Pradnya Paramita.

Dolan, R. Hayden, B.P., Hornberger, G., Zeiman J., and Vincent, M.K., 1972, Classification of the coastal environment of the wold. 1. The Americas charlottesville, Va: Department of environmentals Sciences, University of Virginia, Tech.Rept. 1, 163 p.

ESRI. 1990. Understanding GIS: The Arc/ Info Method Envoronmental System Research Institute. Redlands, CA. United State.

Pemerintah Kota Makassar. 2004. Rencana Tata Ruang Wilayah (RTRW) Kota Makassar Tahun 2004-2013. Makassar: Bappeda, Pemkot Makassar.

[PRWLSDNH] Pusat Riset Wilayah Laut dan Sumberdaya Nonhayati. 2004. Wisata Bahari Di Kepulauan Spermonde Makassar. Jakarta.

[PRWLSDNH] Pusat Riset Wilayah Laut dan Sumberdaya Nonhayati. 2002. Kajian Pengembangan Ekowisata Bahari. Jakarta: Badan Riset Kelautan dan Perikanan, Departemen Kelautan dan Perikanan. 